\title{
Molecular analysis of isoniazid-resistant clinical isolates of Mycobacterium tuberculosis from India
}

\author{
A. Nusrath Unissa, N. Selvakumar*, Sujatha Narayanan, P.R. Narayanan \\ Tuberculosis Research Centre, Indian Council of Medical Research, Mayor V.R. Ramanathan Road, Chetput, Chennai 600 031, India \\ Received 5 July 2007; accepted 16 August 2007
}

\begin{abstract}
The presence of mutations in specific regions of $k a t G$, inhA, oxyR-ahpC and kasA associated with isoniazid (INH)-resistant clinical isolates of Mycobacterium tuberculosis from India were analysed by DNA sequencing. Point mutations in the kat $G$ gene at codon 315 and a mutation at codon 138 were detected in $64.3 \%(45 / 70)$ and $4 \%(1 / 25)$ of isolates, respectively. Polymorphisms at codon 463 of the kat $G$ gene were found both in resistant and sensitive isolates. Mutation at the inhA and $\operatorname{xxy} R-a h p C$ promoter regions occurred in $11.4 \%(8 / 70)$ and $35.0 \%$ (14/40) of the isolates, respectively. No mutation was found to occur in kasA and inhA structural gene regions. Of the 70 resistant isolates studied, 55 (78.6\%) showed mutation in the regions sequenced. This is the first comprehensive molecular analysis of INH resistance in India, which suggests that point mutation rather than deletion and insertion is the major cause of INH resistance.
\end{abstract}

(C) 2007 Elsevier B.V. and the International Society of Chemotherapy. All rights reserved.

Keywords: Mycobacterium tuberculosis; Isoniazid; Resistance; DNA sequencing; Mutation

\section{Introduction}

Tuberculosis (TB) remains a major public health problem in many parts of the world, despite being a controllable, preventable and curable disease. There were an estimated 8.8 million TB cases in 2005, 7.4 million in Asia and sub-Saharan Africa. A total of 1.6 million people died of TB globally [1]. In India, one person dies from TB every minute [2], accounting for nearly $30 \%$ of TB cases in the world. The gravity of the situation has further worsened due to the emergence of multidrug-resistant TB (MDR-TB), i.e. strains resistant to at least two of the first-line TB drugs isoniazid (INH) and rifampicin (RIF), extensive drug-resistant TB (XDR$\mathrm{TB})$, i.e. MDR-TB that is resistant to any fluoroquinolone and at least one of three injectable second-line drugs (capreomycin, kanamycin and amikacin), and HIV-TB. Acquisition of resistance by the bacterium is a random event. In a given mycobacterial population, the chance that a bacterium will acquire multidrug resistance is $10^{-14}\left(1\right.$ in $10^{6}$ mutates to develop INH resistance and 1 in $10^{8}$ mutates to develop

\footnotetext{
* Corresponding author. Tel.: +91 442836 9620; fax: +91 4428362528 E-mail address: selvakumar.nagamiah@gmail.com (N. Selvakumar).
}

RIF resistance), thus isolates resistant to INH are seen with increasing frequency [3].

INH is being extensively used as the frontline anti-TB drug and a choice for chemoprophylaxis. It is proposed that INH enters the cell as a prodrug by passive diffusion and is activated by catalase-peroxidase, encoded by $k a t G$, to generate free radicals that transform INH into its active form [4]. Studies have shown that inhA, encoding enoyl-acyl carrier protein (ACP) reductase, and kasA, encoding for ketoacyl-ACP synthase, are the important intracellular targets for activated INH. These enzymes are involved in elongation of fatty acids intermediate in the biosynthetic pathway [5,6]. In addition, mutations in the oxyR-ahpC intergenic region have been identified in INH-resistant isolates [7].

Reports from all over the world suggest that mutations responsible for INH resistance reside in katG, inhA, ahpC, kas $A$ and other genes. Of these, three reports concerned Indian isolates. Two of the reports lack information pertaining to Ser315Thr substitution, a marker of INH resistance $[8,9]$. In the third study, information was given for 29 isolates [10]. Therefore, a comprehensive molecular study is required that could provide a clear picture of the prevailing resistance mechanisms for INH in India. Hence, the present study was aimed at screening clinical isolates of Mycobac- 
terium tuberculosis in different regions of India, especially South India. It was shown that INH-resistant isolates from South India have low catalase activity [11]. Thus, it would be of interest to determine the mutational pattern in the genes associated with INH resistance from South Indian isolates.

\section{Material and methods}

\subsection{Characterisation of M. tuberculosis clinical isolates}

The study included 80 clinical isolates collected from the Tuberculosis Research Centre. Ten isolates were sensitive to INH and 70 isolates were INH-resistant (Table 1).

Drug sensitivity testing was performed using LowensteinJensen medium, and INH sensitivity was determined by the minimum inhibitory concentration (MIC) method. In this study, isolates with three different MIC values of 1 , 5 and $>5 \mathrm{mg} / \mathrm{L}$ were considered resistant and isolates with MICs $\leq 0.2 \mathrm{mg} / \mathrm{L}$ were considered sensitive.

Among the 70 resistant isolates, 40 were MDR strains and 30 were resistant to INH with or without resistance to other drugs. Complete resistance profiles were available for 48 of the 70 INH-resistant isolates. Of these 48 isolates, the frequency of resistance to other drugs was as follows: streptomycin, 19 (39.6\%); RIF, 30 (62.5\%); ethambutol, 18 (37.5\%); kanamycin, 6 (12.5\%); ethionamide, 18 (37.5\%); and ofloxacin, $12(25.0 \%)$. The susceptibility profile for the remaining 22 isolates with $\mathrm{MIC} \geq 5 \mathrm{mg} / \mathrm{L}$ with respect to other drugs was not available.

\subsection{Preparation of DNA}

Genomic DNA was prepared using sodium chloride and cetyltrimethylammonium bromide method as described previously [8].

\subsection{Amplification of genes}

Polymerase chain reaction (PCR) was performed with 30 cycles of amplification $\left(1 \mathrm{~min}\right.$ at $95^{\circ} \mathrm{C}, 30 \mathrm{~s}$ at $60^{\circ} \mathrm{C}$ and $1 \mathrm{~min}$ at $72{ }^{\circ} \mathrm{C}$ ). The primer sequences for the respective genes are given in Table 2. The amplicons were purified using a GFX column (Amersham Biosciences Ltd., Little Chalfont, UK) according to the manufacturer's instructions.

\subsection{DNA sequencing and analysis}

In this study, mutational analysis was performed in three structural regions of the katG gene spanning codons 110-200, 261-331 and 401-537, two regions (one regulatory and one structural) of the inhA gene, an intergenic region in $\operatorname{oxy} R-a h p C$ (Fig. 1) and a region from the kasA gene. Sequencing of the amplicons was carried out using an automated DNA sequencer (ABI Prism 310 Genetic Analyzer; Applied Biosystems, Foster City, CA). The data obtained were compared with sequences
Table 1

Mutational profile of isoniazid-resistant Mycobacterium tuberculosis clinical isolates in India

\begin{tabular}{|c|c|c|c|c|}
\hline Strain no. (state) ${ }^{\mathrm{a}}$ & Resistance & $k a t G^{b}$ & $\operatorname{inh} A^{\mathrm{c}}$ & $\operatorname{ahpC}$ \\
\hline $1(\mathrm{TN})$ & MDR & ATC & & \\
\hline $2(\mathrm{TN})$ & $\mathrm{H}$ & & & \\
\hline $3(\mathrm{TN})$ & MDR & $\mathrm{ACC}$ & & \\
\hline $4(\mathrm{TN})$ & $\mathrm{H}$ & & & \\
\hline $5(\mathrm{TN})$ & $\mathrm{H}$ & & & \\
\hline $6(\mathrm{TN})$ & MDR & ACC & & \\
\hline $7(\mathrm{TN})$ & $\mathrm{H}$ & $\mathrm{ACC}$ & & \\
\hline $8(\mathrm{TN})$ & MDR & & & $\begin{array}{l}\mathrm{T} \rightarrow \mathrm{G},-34 \mathrm{bp}^{\mathrm{d}} \\
\mathrm{G} \rightarrow \mathrm{A},-46 \mathrm{bp}\end{array}$ \\
\hline $9(\mathrm{TN})$ & MDR & $\mathrm{ACC}$ & & \\
\hline $10(\mathrm{TN})$ & MDR & $\mathrm{ACC}$ & & \\
\hline $11(\mathrm{TN})$ & MDR & $\mathrm{ACC}$ & & \\
\hline $12(\mathrm{TN})$ & MDR & $\mathrm{ACC}$ & & \\
\hline $13(\mathrm{TN})$ & $\mathrm{H}$ & & & \\
\hline $14(\mathrm{TN})$ & $\mathrm{H}$ & & & \\
\hline $15(\mathrm{TN})$ & MDR & ACC & & \\
\hline $16(\mathrm{TN})$ & MDR & & & \\
\hline $17(\mathrm{TN})$ & MDR & $\mathrm{AAC}$ & & \\
\hline $18(\mathrm{TN})$ & $\mathrm{H}$ & & $\mathrm{C} \rightarrow \mathrm{T}$ & \\
\hline $19(\mathrm{TN})$ & $\mathrm{H}$ & $\mathrm{AAC}$ & & \\
\hline $20(\mathrm{TN})$ & MDR & $\mathrm{ACC}$ & & \\
\hline $21(\mathrm{TN})$ & MDR & $\mathrm{ACC}$ & & \\
\hline $22(\mathrm{TN})$ & $\mathrm{H}$ & & $\mathrm{C} \rightarrow \mathrm{T}$ & \\
\hline $23(\mathrm{TN})$ & MDR & $\mathrm{ACC}$ & & \\
\hline $24(\mathrm{TN})$ & MDR & & & \\
\hline $25(\mathrm{TN})$ & $\mathrm{H}$ & $\mathrm{ACC}$ & & \\
\hline $26(\mathrm{TN})$ & $\mathrm{H}$ & $\mathrm{ACC}$ & & \\
\hline $27(\mathrm{TN})$ & $\mathrm{H}$ & $\mathrm{ACC}$ & & \\
\hline $28(\mathrm{TN})$ & MDR & & & \\
\hline $29(\mathrm{AP})$ & MDR & $\mathrm{ACC}$ & & \\
\hline $30(\mathrm{AP})$ & $\mathrm{H}$ & & & \\
\hline $31(\mathrm{AP})$ & $\mathrm{H}$ & $\mathrm{ACC}$ & & \\
\hline $32(\mathrm{AP})$ & MDR & & & $\mathrm{G} \rightarrow \mathrm{A},-46 \mathrm{bp}$ \\
\hline $33(\mathrm{AP})$ & MDR & & $\mathrm{C} \rightarrow \mathrm{T}$ & \\
\hline 34 (AP) & MDR & $\mathrm{ACC}$ & & \\
\hline $35(\mathrm{AP})$ & MDR & & & \\
\hline $36(\mathrm{AP})$ & MDR & & $\mathrm{C} \rightarrow \mathrm{T}$ & \\
\hline $37(\mathrm{AP})$ & MDR & ACC & & \\
\hline 38 (KA) & $\mathrm{H}$ & & & \\
\hline 39 (KA) & $\mathrm{H}$ & $\mathrm{ACC}$ & $\mathrm{C} \rightarrow \mathrm{T}$ & \\
\hline $40(\mathrm{~K})$ & $\mathrm{H}$ & $\mathrm{ACC}$ & & \\
\hline 41 (GU) & MDR & $\mathrm{ACC}$ & & $\mathrm{G} \rightarrow \mathrm{A},-6 \mathrm{bp}$ \\
\hline 42 (GU) & $\mathrm{H}$ & & & \\
\hline $43(\mathrm{GU})$ & $\mathrm{H}$ & $\mathrm{ACC}$ & & $\mathrm{T} \rightarrow \mathrm{A},-34 \mathrm{bp}$ \\
\hline $44(\mathrm{G})$ & $\mathrm{H}$ & $\mathrm{ACC}$ & & \\
\hline $45(\mathrm{G})$ & MDR & $\mathrm{ACC}$ & & \\
\hline $46(\mathrm{G})$ & MDR & $\mathrm{ACC}$ & & \\
\hline $47(\mathrm{G})$ & MDR & ACC & & $\mathrm{G} \rightarrow \mathrm{A},-6 \mathrm{bp}$ \\
\hline 48 (A) & MDR & & & $\mathrm{C} \rightarrow \mathrm{T},-30 \mathrm{bp}$ \\
\hline $49(\mathrm{TN})$ & MDR & & & \\
\hline $50(\mathrm{TN})$ & $\mathrm{H}$ & & & \\
\hline $51(\mathrm{TN})$ & MDR & $\mathrm{AAC}$ & & $\mathrm{G} \rightarrow \mathrm{A},-46 \mathrm{bp}$ \\
\hline $52(\mathrm{TN})$ & $\mathrm{H}$ & $\mathrm{ACC}$ & & \\
\hline $53(\mathrm{TN})$ & $\mathrm{H}$ & ACC & & $\mathrm{G} \rightarrow \mathrm{A},-46 \mathrm{bp}$ \\
\hline $54(\mathrm{TN})$ & $\mathrm{H}$ & $\mathrm{ACC}$ & & \\
\hline $55(\mathrm{TN})$ & $\mathrm{H}$ & $\mathrm{ACC}$ & & $\mathrm{G} \rightarrow \mathrm{A},-46 \mathrm{bp}$ \\
\hline $56(\mathrm{TN})$ & MDR & $\mathrm{ACC}$ & & \\
\hline $57(\mathrm{TN})$ & MDR & ACC & & \\
\hline $58(\mathrm{TN})$ & $\mathrm{H}$ & $\mathrm{ACC}$ & & \\
\hline $59(\mathrm{TN})$ & MDR & & $\mathrm{C} \rightarrow \mathrm{T}$ & \\
\hline $60(\mathrm{TN})$ & MDR & $\mathrm{ACC}$ & & $\mathrm{G} \rightarrow \mathrm{A},-46 \mathrm{bp}$ \\
\hline
\end{tabular}


Table 1 (Continued)

\begin{tabular}{lllll}
\hline Strain no. (state) & Resistance & $k a t G^{\mathrm{b}}$ & $i n h A^{\mathrm{c}}$ & $a h p C$ \\
\hline $61(\mathrm{TN})$ & $\mathrm{H}$ & $\mathrm{AGC}^{\mathrm{e}}$ & & $\mathrm{G} \rightarrow \mathrm{A},-46 \mathrm{bp}$ \\
$62(\mathrm{TN})$ & MDR & & & $\mathrm{C} \rightarrow \mathrm{T},-30 \mathrm{bp}$ \\
$63(\mathrm{TN})$ & MDR & ACC & $\mathrm{C} \rightarrow \mathrm{T}$ & \\
$64(\mathrm{TN})$ & $\mathrm{H}$ & $\mathrm{ACC}$ & & $\mathrm{G} \rightarrow \mathrm{A},-46 \mathrm{bp}$ \\
$65(\mathrm{TN})$ & $\mathrm{H}$ & $\mathrm{ACC}$ & & \\
$66(\mathrm{TN})$ & $\mathrm{H}$ & & & \\
$67(\mathrm{TN})$ & MDR & ACC & $\mathrm{C} \rightarrow \mathrm{T}$ & \\
$68(\mathrm{TN})$ & MDR & ACC & & \\
$69(\mathrm{TN})$ & MDR & ACC & & \\
$70(\mathrm{TN})$ & MDR & ACC & & \\
\hline
\end{tabular}

TN, Tamil Nadu; AP, Andhra Pradesh; KA, Karnataka; K, Kerala; GU, Gujarat; G, Goa; A, Assam; MDR, multidrug resistance (strains resistant to at least two of the first-line tuberculosis drugs isoniazid and rifampicin); $\mathrm{H}$, isoniazid-resistant isolates.

${ }^{\text {a }}$ TN strains (Nos. 1-28) and other state strains (Nos. 29-48) with minimum inhibitory concentration (MIC) of $1 \mathrm{mg} / \mathrm{L}$; strains with MIC of $5 \mathrm{mg} / \mathrm{L}$ (Nos. 49-58) and >5 mg/L (Nos. 59-70).

b Substitution at codon 315 .

c Conversion at $-15 \mathrm{bp}$.

${ }^{\mathrm{d}}$ Novel mutation.

e AAC to AGC at codon 138

from the EMBOSS database using the alignment tool (http://www.ebi.ac.uk/emboss/align). The GenBank accession numbers are X68081 for kat $G, \mathrm{U} 41388$ for inhA, U16243 for $a h p C$ and BX842579 for kasA.

\section{Results and discussion}

\subsection{Mutational analysis in MDR and non-MDR \\ INH-resistant isolates}

In an effort to gain molecular insights into INH resistance at the genomic level, a total of 80 samples comprising 70 resistant and 10 sensitive isolates, along with one $M$.
(A)
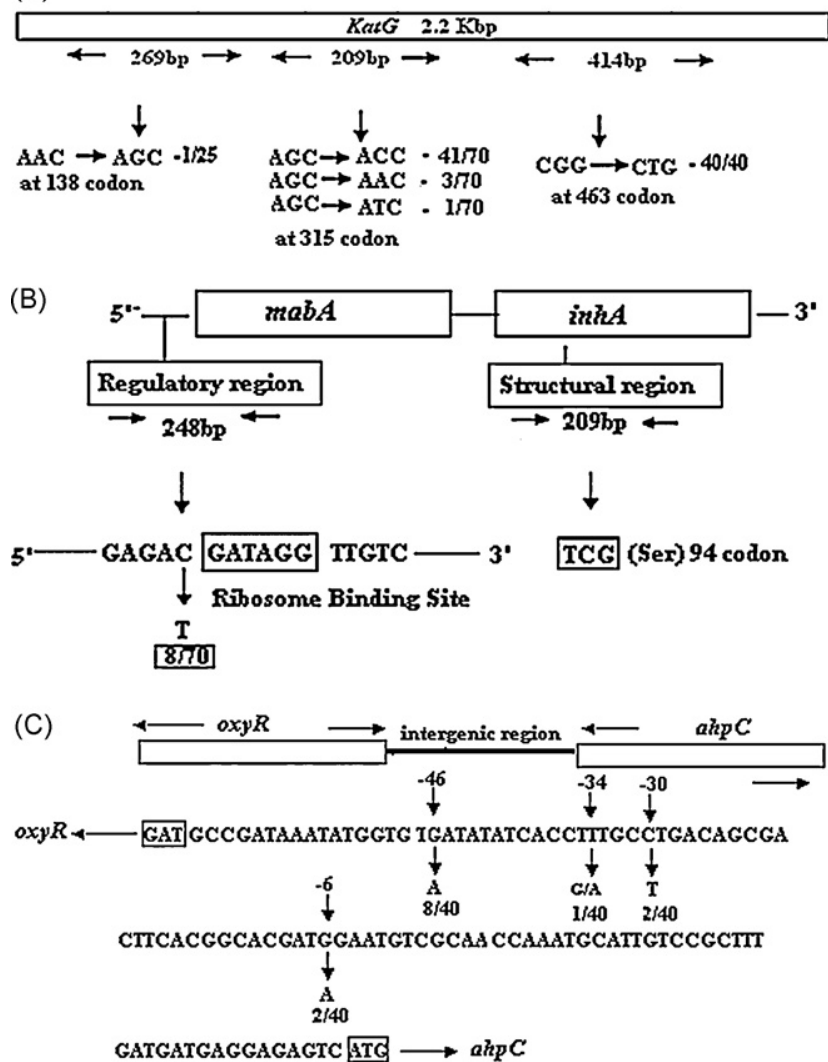

Fig. 1. Schematic representation of sequenced regions, indicating the mutations associated with isoniazid resistance identified in this study (with due modification from [12]).

tuberculosis $\mathrm{H} 37 \mathrm{Rv}$ as control, were included in the mutational analysis. None of the sensitive isolates had mutations. The overall frequency of mutation was $87.5 \%$ (35/40) in MDR isolates and $66.7 \%$ (20/30) in non-MDR INH-resistant

Table 2

Primers used in the study

\begin{tabular}{|c|c|c|c|}
\hline Genes (region) & Primer sequences $\left(5^{\prime}-3^{\prime}\right)$ & Amplicon size (bp) & Reference \\
\hline katG $(\mathrm{S})$ & $\begin{array}{l}\text { F-C C G G C A C C T A C C G C A T C C A C } \\
\text { R-GCCC C A A A G A C C T C A T C G G }\end{array}$ & 269 & [12] \\
\hline katG $(\mathrm{S})$ & $\begin{array}{l}\text { F-G A A A C A G C G G C GC T G G A T C G T } \\
\text { R-G T T G T C C C А T T T C G T C G G G G }\end{array}$ & 209 & [12] \\
\hline$k a t G(\mathrm{~S})$ & $\begin{array}{l}\text { F-C GA G G A A T T G GCCGACGA G T T } \\
\text { R-C G GCGCCGCGGAGT T GA A T A }\end{array}$ & 414 & [9] \\
\hline $\operatorname{inh} A(\mathrm{R})$ & $\begin{array}{l}\text { F-C C T C G C T G C C C A G A A A G G G A } \\
\text { R-A T C C C C C G GT T T C C T C C G G T }\end{array}$ & 248 & [9] \\
\hline $\operatorname{inh} A(\mathrm{~S})$ & 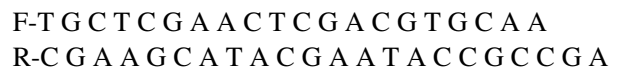 & 209 & [13] \\
\hline $\operatorname{ahp} C(\mathrm{R})$ & $\begin{array}{l}\text { F-A C C AC T GC T T T GCC GCCACC } \\
\text { R-C C GA T GA G A GCG T G A GC T G }\end{array}$ & 236 & {$[14]$} \\
\hline $\operatorname{kas} A(\mathrm{~S})$ & $\begin{array}{l}\text { F-A T C GCG GCG T T C T C C A T G A } \\
\text { R-C GCG G G GC A C C A T A T }\end{array}$ & 224 & {$[14]$} \\
\hline
\end{tabular}

S, structural; R, regulatory; F, forward; R, reverse. 
isolates. Twenty-five MDR isolates had Ser (AGC) to Thr (ACC), two isolates had Ser to Asn (AAC) and one isolate had Ser to Ile (ATC) substitution at codon 315 in the $k a t G$ gene. Five of the isolates had $\mathrm{C} \rightarrow \mathrm{T}$ conversion at position -15 of $i n h A$ regulatory region. Of 8 isolates with mutation in the oxyR-ahpC intergenic region, three had $\mathrm{G} \rightarrow \mathrm{A}$ at position -46 , two had $\mathrm{C} \rightarrow \mathrm{T}$ at position -30 , two had $\mathrm{G} \rightarrow \mathrm{A}$ at position -6 and one had $\mathrm{T} \rightarrow \mathrm{G}$ at position -34 . Numbering of intergenic region nucleotides is based on the position relative to the mRNA initiation site.

In the case of non-MDR INH-resistant isolates, 18 isolates showed mutations in the $k a t G$ gene (16 with ACC, one with $\mathrm{AAC}$ at codon 315 and one with AGC at codon 138). $\mathrm{C} \rightarrow \mathrm{T}$ changes were observed in three isolates in the inhA gene. Four of the isolates had $\mathrm{G} \rightarrow \mathrm{A}$ at position -46 and one had $\mathrm{T} \rightarrow \mathrm{A}$ at position -34 in $\operatorname{oxy} R-a h p C$ intergene region. Our study indicates the presence of a higher frequency of mutations in MDR compared with in non-MDR isolates.

\subsection{Relationship between drug susceptibility testing and mutational profile}

Differences were seen amongst the isolates with MIC values of $1 \mathrm{mg} / \mathrm{L}$ and $\geq 5 \mathrm{mg} / \mathrm{L}$ (frequency of mutation $75 \%$ vs. $83 \%$, respectively). In 22 isolates with high MIC values of $\geq 5 \mathrm{mg} / \mathrm{L}$, the mutation rate was $77 \%$ in $\mathrm{katG}, 13.6 \%$ in inhA and $31.8 \%$ at the $\operatorname{oxy} R-a h p C$ locus. In contrast, in the remaining 48 isolates with MIC values of $1 \mathrm{mg} / \mathrm{L}$, the mutation rate was found to be $60 \%$ for $k a t G, 10.4 \%$ for inhA and $12.5 \%$ for $a h p C$ region, suggesting a strong correlation between the MICs of INH and the levels of mutation in our isolates.

Some differences in the distribution patterns of resistance mutations for the different states of India were detected, as indicated in Table 1.

\subsection{Determination of frequency of mutation at the respective loci}

Of the 70 phenotypically resistant isolates that were sequenced, 45 (64.3\%) were found to be genotypically resistant via $k a t G$ mutations at codon 315 by the occurrence of ACC in $41(58.6 \%)$, AAC in $3(4.3 \%)$ and ATC in $1(1.4 \%)$ isolates. Polymorphisms at codon 463 of $k a t G$ gene were found in all (40 resistant and 10 sensitive) isolates.

A mutation at codon 138 having $\mathrm{AAC} \rightarrow \mathrm{AGC}$ conversion was found in 1 of 25 isolates at the $\mathrm{N}$-terminal region of the $k a t G$ gene, suggesting its role in the catalytic mechanism of the $k a t G$ protein, which is in accordance with the findings of Rouse et al. [15].

In this study, the observed frequency of mutation in the upstream region of the inhA locus was ca. 11\%. Interestingly, all mutations were of the same kind and were not in the other nucleotides of the regulatory region as reported by others $[12,13]$.
The mutations identified in the structural part of inhA result in INH resistance due to a reduced binding affinity of INH-NAD adduct for enoyl reductases [5]. The absence of mutation Ser94Ala in the structural region of the inhA gene in our study is in agreement with a report from Korea [13].

In 40 resistant isolates sequenced for the oxyR-ahpC intergenic region, various types of mutations, comprising of transversions $(\mathrm{T} \rightarrow \mathrm{G}$ and $\mathrm{T} \rightarrow \mathrm{A}$ at position -34$)$ and transitions $(\mathrm{G} \rightarrow \mathrm{A}$ at position $-46, \mathrm{G} \rightarrow \mathrm{A}$ at position -6 and $\mathrm{C} \rightarrow \mathrm{T}$ at position -30 ) accounting to $35 \%$, were found to occur. Instead of the common mutation $\mathrm{T} \rightarrow \mathrm{C}$ or $\mathrm{A}$, a novel mutation with $\mathrm{T} \rightarrow \mathrm{G}$ transition at position -34 was found in this study that, to the best of our knowledge, has not been reported elsewhere in the literature.

No substitution was seen at codon 269 of the kasA structural region in 25 isolates and this mutation has been known as a gene polymorphism that is unrelated to INH resistance. A study from Singapore has reported that mutation of kasA does not represent a frequent event associated with INH resistance [16]. In the present study, lack of mutation in the kasA gene suggests that this is a rare event associated with INH resistance.

There were no occurrences of mutation in any of the sequenced regions in 15 of $70 \mathrm{INH}$-resistant clinical isolates, suggesting the existence of other undefined mechanisms of INH resistance in the phenotypically resistant isolates. Thus, a collective mutation frequency of $78.6 \%$ (55/70) is evident in our isolates.

\subsection{Relative comparison between the sequenced regions}

The frequency of mutations associated with INH resistance was $65.7 \%$ in $k a t G$ gene, $11.4 \%$ in inhA gene and $35 \%$ in oxyR-ahpC intergenic region. A relative comparison between the three loci in frequency distribution showed that $3(4.3 \%)$ had mutations in $k a t G$ and $i n h A$, whereas 9 (22.5\%) had mutations in $k a t G$ and $a h p C$. No isolates were found to have a mutation in both $\operatorname{ahpC}$ and inhA genes.

The findings from this study are consistent with previous studies of mutational patterns in INH resistance. The results of our study suggest that point mutations appear to be the major cause for INH resistance, in contrast to a study from North India where deletion and insertion were observed more than substitution [9]. Our study also suggests the existence of other undefined mechanisms of INH resistance in phenotypically resistant isolates that were not associated with any genotypic mutations. Hence, the genetic mechanism of INH resistance in M. tuberculosis is highly complex involving several genes, and much remains to be explored to achieve a better understanding of the complex mechanism. Studies of this kind will enable a better understanding of the molecular mechanisms of drug resistance, facilitating the development of improved diagnostics to detect resistant organisms rapidly as well as providing insights into drug-target interactions to aid the rational design of more efficacious drugs. 


\section{Acknowledgments}

We are grateful to Mrs C. Suganthi, Immunology Department, Tuberculosis Research Centre, for excellent technical help in the laboratory.

Funding: This work was supported by an Indian Council of Medical Research grant for Research Fellowship.

Competing interests: None declared.

Ethical approval: Not required.

\section{References}

[1] World Health Organization. WHO report 2007. Global tuberculosis control: surveillance, planning and financing. WHO/HTM/TB/ 2006.376. Geneva, Switzerland: WHO; 2006.

[2] TBC India. Tuberculosis key facts. http://www.tbcindia.org/key.asp. [accessed 5 September 2007].

[3] Harkin TJ, Harris HW. Treatment of multidrug resistant tuberculosis. In: Rom NW, Garay S, editors. Tuberculosis. Boston: MA: Little, Brown \& Company; 1995. p. 843-50.

[4] Zhang Y, Heym B, Allen B, et al. The catalase-peroxidase gene and isoniazid resistance of Mycobacterium tuberculosis. Nature 1992;358:591-3.

[5] Banerjee A, Dubnau E, Quemard A, et al. inhA, a gene encoding a target for isoniazid and ethionamide in Mycobacterium tuberculosis. Science 1994;263:227-30.

[6] Mdluli KR, Slayden A, Zhu Y, et al. Inhibition of a Mycobacterium tuberculosis $\beta$-ketoacyl ACP synthase by isoniazid. Science 1998;280:1607-10.

[7] Sreevatsan S, Pan X, Zhang Y, et al. Analysis of the oxyR-ahpC region in isoniazid-resistant and -susceptible Mycobacterium tuber- culosis complex organisms recovered from diseased humans and animals in diverse localities. Antimicrob Agents Chemother 1997;41: 600-6.

[8] Siddiqi N, Shamim M, Jain NK, et al. Molecular genetic analysis of multidrug resistance in Indian isolates of Mycobacterium tuberculosis. Mem Inst Oswaldo Cruz 1998;93:589-94.

[9] Siddiqi N, Shamim M, Hussain S, et al. Molecular characterization of multidrug-resistant isolates of Mycobacterium tuberculosis from patients in North India. Antimicrob Agents Chemother 2002;46:443-50.

[10] Harris KA, Mukundan Jr U, Musser JM, et al. Genetic diversity and evidence for acquired antimicrobial resistance in Mycobacterium tuberculosis at a large hospital in South India. Int J Infect Dis 2000;4:140-7.

[11] Mitchison DA, Selkon JB, Lloyd J. Virulence in the guinea-pig, susceptibility to hydrogen peroxide, and catalase activity of isoniazid-sensitive tubercle bacilli from South Indian and British patients. J Pathol Bacteriol 1963;86:377-86.

[12] Kiepiela P, Bishop KS, Smith AN, et al. Genomic mutations in the $k a t G$, inhA and $a h p C$ genes are useful for the prediction of isoniazid resistance in Mycobacterium tuberculosis isolates from Kwazulu Natal, South Africa. Tuber Lung Dis 2000;80:47-56.

[13] Lee H, Cho SN, Bang HE, et al. Exclusive mutations related to isoniazid and ethionamide resistance among Mycobacterium tuberculosis isolates from Korea. Int J Tuberc Lung Dis 2000;4:441-7.

[14] Rindi L, Bianchi L, Tortoli E, et al. Mutations responsible for Mycobacterium tuberculosis isoniazid resistance in Italy. Int J Tuberc Lung Dis 2005;9:94-7.

[15] Rouse DA, DeVito JA, Li Z, et al. Site-directed mutagenesis of the katG gene of Mycobacterium tuberculosis: effects on catalase-peroxidase activities and isoniazid resistance. Mol Microbiol 1996;22:58392.

[16] Lee AS, Lim IH, Tang LLH, et al. Contribution of kasA analysis to detection of isoniazid-resistant Mycobacterium tuberculosis in Singapore. Antimicrob Agents Chemother 1999;43:2087-9. 